\title{
Pela consolidação da Pesquisa em arquitetura
}

\author{
Mônica Junqueira de Camargo
}

A ampliação dos cursos de arquitetura no país que, hoje, ultrapassam duas centenas, tem tornado a docência uma opção profissional muito procurada, aumentando o interesse pela pósgraduação e, conseqüentemente, impulsionando as atividades de pesquisa. A FAUUSP, cuja pósgraduação foi criada em 1972, inicialmente o mestrado e, a partir dos anos 80, o doutorado, permanecendo única por muitos anos e, ainda hoje, o maior programa do país, compartilha, atualmente, com muitas outras instituições, a formação de docentes e pesquisadores. Entretanto, se comparada a outras áreas do conhecimento, a institucionalização da pesquisa em arquitetura é ainda recente no país, não completou nem meio século, enquanto outras são seculares. 0 engajamento de campos com metodologias distintas, característico da arquitetura, que abrange da criação artística às questões técnico-construtivas, do planejamento à sociologia e estatística, da crítica à história, a pesquisa em arquitetura vem, paulatinamente, conquistando sua autonomia disciplinar. A trajetória da revista Pós é testemunha da consolidação da pesquisa científica em arquitetura, registrando os avanços no estabelecimento de uma referência própria. As edições mais recentes evidenciam um maior entrosamento dos textos científicos com a estrutura acadêmica, no âmbito da docência, da pesquisa e da extensão, tanto da pós como da graduação.

Tem-se registrado uma maior submissão de trabalhos, em distintos estágios da pesquisa, inclusive a continuidade de trabalhos publicados anteriormente; uma diversificação de temas, bem como uma proliferação de suas procedências, o que tem tornado o processo de avaliação mais complexo. Se, por um lado, o envolvimento dos docentes com a rotina editorial é ainda irregular nem todos respondem às solicitações em tempo hábil, por outro, as análises têm sido mais rigorosas, havendo uma cobrança de mais qualidade dos textos e não sendo rara a necessidade de um terceiro parecer para desempate, que acaba por comprimir os prazos de revisão e diagramação, para que não se comprometa a periodicidade. Pelo fluxo de trabalho da revista Pós, que conta com o privilégio da dedicação da jornalista Lina Rosa e a experiência do arquiteto José Tadeu Maia, é possível identificar um crescente amadurecimento do processo de pesquisa em arquitetura. A sua inserção no Portal USP de Revistas Científicas, graças à dedicação da Comissão de Credenciamento, garantindo a versão eletrônica com alcance muito mais amplo do que a edição em papel, cobrirá, em parte, a dificuldade de sua distribuição, a qual, apesar das inúmeras tentativas, continua sendo um dos grandes entraves do processo editorial.

Esta edição, integrada por dez artigos científicos, a discutirem questões urbanas, arquitetônicas e tecnológicas, apresenta o estágio atual de algumas das pesquisas de cada uma dessas áreas.

A seção Depoimentos traz a público a interessante trajetória do raro exemplar do tratado de Vitrúvio, de 1586, que, a partir de 2007, passou a integrar o acervo da biblioteca da FAU, por meio da qual foi possível recuperar a não menos interessante contribuição do arquiteto Stipan Milic, o qual trabalhou em São Paulo nas décadas de 1960 e 1970, com importante participação no projeto do Conjunto Habitacional Zezinho Magalhães Prado.

O primeiro artigo, Brazil builds Em Campinas: Uma ferramenta simbólica da estratégia de legitimação de implantação do Plano de Melhoramentos Urbanos, de Silvia A. Palazzi Zakia, apresenta a repercussão da paradigmática exposição americana sobre a produção arquitetônica brasileira, realizada em 1943 no Museu de Arte Moderna de Nova York, para além daquelas amplamente divulgadas pela historiografia. Segundo a pesquisadora, a instalação dessa exposição na cidade de Campinas foi fruto de uma intricada combinação de interesses, que envolvia, simultaneamente, os objetivos da elite e do poder púbico local: implantar um grande projeto de inserção dessa cidade na modernidade, dando impulso à execução do Plano de Melhoramentos Urbanos, de Prestes Maia, contratado pela prefeitura de Campinas em 1934 e até então não colocado em prática. 
Em O sul por testemunha: Declínio da hegemonia corbusiano-carioca e ascensão da dissidência paulista na arquitetura brasileira anos 50, Luís Henrique Haas Luccas identifica, na arquitetura gaúcha, a mudança de referência, em um primeiro momento, de forte ascendência carioca para, a partir dos anos 50, adquirir inspiração majoritariamente paulista, que teve no concurso para o Palácio Legislativo, na cidade de Porto Alegre, vencido pelos arquitetos sediados em São Paulo Wolfang e Gregorio Zolko, seu marco inaugural. Recuperando os mestres e as obras paradigmáticas da produção paulista, Luccas aponta a influência dessa arquitetura na produção arquitetônica gaúcha que quebrou a hegemonia da influência carioca de forte acento corbusiano.

O estilinho internacional, uma oportuna versão para o português de Luís Espallargas Gimenez do texto de Hélio Piñon, recupera a real contribuição da arquitetura, atabalhoadamente classificada de estilo internacional, em contraposição à produção pós-moderna que se alçou como sua crítica, pretendendo superar seus equívocos. Valendo-se dos marcos do estilo internacional, Piñon destaca as várias conquistas dessa arquitetura que, segundo ele, soube incorporar a clareza formal do classicismo, a perfeição formal do artesanato e a subjetividade transcendente, inerente ao ato de conceber, tendo muito mais qualidade do que muitas das obras concebidas como revisionistas do corolário moderno, inclusive premiadas em concursos ou estampadas nas capas de revista.

Renato Anelli põe em debate, sob o título de Ponderações sobre os relatos da trajetória de Lina Bo Bardi na Itália, as diferentes versões de seu primeiro e, de acordo com o pesquisador, mais importante texto de sua fase italiana, intitulado Currículo literário. Sua cuidadosa pesquisa permitiu confrontar as manifestações de Carlo Pagani, colaborador de Lina em suas atividades na Itália, com uma entrevista de Francisco Tentori, de 1989, sobre a polêmica criada entre as versões de Lina e Pagani. Com base na documentação de época encontrada nos arquivos e bibliotecas italianos e no Instituto Bardi, Anelli busca identificar as diferenças dessas interpretações, bem como suas causas.

O texto Nada vem do nada: Por uma revisão contemporânea do conceito de tipo edilício, de Cristiano Felipe Borba do Nascimento, discute a origem e as diferentes interpretações, ao longo da história e pelos diversos autores, do termo tipo na cultura arquitetônica. A partir do registro de Quatremère de Quincy, em 1832, o autor percorre o ensino de projeto na França, nos séculos 18 e 19; a apropriação, pelos italianos, a partir das considerações de Muratori, instituindo a tipologia edilícia como uma disciplina, com destaque às interpretações de Argan e Rossi, que tratam da relação entre arquitetura e cidade por meio do tipo arquitetônico; alcançando até as revisões mais recentes como as de Hillier, Hanson e Markus. Nascimento conclui com a necessidade de uma atualização na leitura desse termo, a partir do resgate da idéia original de Quincy, instigando novas investigações que permitam ampliar o conhecimento científico sobre o ambiente construído.

Diante das mudanças na organização do trabalho de arquitetura, decorrentes, sobretudo, dos avanços tecnológicos das últimas décadas, Francisco Segnini Jr. analisa em Arte, técnica e mercado: O trabalho do arquiteto, as tensões surgidas nas novas formas de trabalho. Sua pesquisa, baseada em entrevistas e depoimentos, foi estruturada em duas etapas: uma primeira, envolvendo 206 profissionais atuantes no período de 1985 a 2000, quando se verificou uma grande difusão da informática, e uma segunda que contou com a participação de 31 arquitetos formados pela FAUUSP, trabalhando no período de consolidação do uso de instrumentos eletrônicos na produção do projeto arquitetônico.

O artigo seguinte, Oito critérios para a pesquisa acadêmica em áreas de prática projetual, de Michael Biggs e Daniela Büchler, dá continuidade ao trabalho desses mesmos autores, publicado na edição n. 26 desta revista e avança, perscrutando a complexidade da pesquisa científica em projeto arquitetônico. Nessa etapa, os autores buscam estabelecer as possíveis relações entre a pesquisa como prática projetual e como atividade acadêmica e identificar problemas comuns de pesquisa nas diversas disciplinas. Adotando a experiência do Reino Unido como recorte para a análise, os autores definem quatro critérios genéricos e quatro específicos de cada disciplina, testados em alguns estudos de caso.

Daniela Tunes Zilio apresenta, em A evolução da caixa cênica - Transformações sociais e tecnológicas no desenvolvimento da dramaturgia e da arquitetura teatral, os resultados da pesquisa 
sobre os desafios de projetar-se um espaço teatral, desenvolvida como iniciação científica. Esse trabalho identificou a importância do conhecimento sobre a dramaturgia, segundo as autoras, tão necessário quanto as questões tecnológicas, como as de acústica e visibilidade. O levantamento da evolução do espaço teatral permitiu estabelecer suas principais mudanças e contribuições ao longo da História, atendo-se a analisar, com mais cuidado, as novas vertentes brasileiras que invocam a construção de espaços de tipologia frontal, nos quais diversos programas artísticos apresentados utilizam o mesmo espaço físico, que se valem da tecnologia para minimizar as limitações inerentes a esses espaços.

No artigo Sistema de avaliação de edifícios de saúde, Augusto Guelli, considerando a influência positiva do espaço na recuperação dos pacientes, aponta a importância de definir-se critérios confiáveis para a avaliação desses espaços. O autor analisa os sistemas utilizados no Brasil e apresenta o sistema AEDET - Achieving Excellence Design Evaluation Toolkit, desenvolvido na Inglaterra em 2002, que busca avaliar a qualidade do espaço quanto à percepção, à função e à técnica. A partir de sua adaptação à realidade brasileira, esse sistema foi testado por uma equipe, sob a coordenação de Guelli, no Hospital Geral Pirajussara, com capacidade para 299 leitos, com resultados muito positivos a sugerirem que a difusão do AEDET pode constituir um avanço importante na avaliação e verificação da qualidade dos edifícios de saúde.

A seção de artigos científicos é encerrada com O NCS - Natural Color System e possíveis aplicações no projeto arquitetônico, de João Carlos de Oliveira César, que discute, a partir da participação da cor na criação arquitetônica, os principais sistemas de notação cromática, concentrando-se, em seguida, na análise do NCS, dada sua difusão no meio arquitetônico. Esse sistema, adotado como padrão em alguns países e como referência de trabalhos acadêmicos, que tem por base as nuances cromáticas, constitui uma ferramenta útil na concepção projetual e também na execução da obra, uma vez que garante a fidelidade entre proposta e produto final.

O Seminário de Estudos sobre Restauração Arquitetônica: "Temas Recentes no Restauro na Itália" foi detalhadamente registrado na seção Conferências na FAUUSP pelos professores responsáveis Beatriz Mugayar Kühl, Beatrice Vivio, Alessandro Pergoli Campanelli e Alessandra Cerroti. Esse seminário integra um programa de cooperação entre Faculdade de Arquitetura Valle Giulia da Universidad degli Studi di Roma "La Sapienza" e a FAUUSP, que visa estimular a troca de conhecimento no campo da restauração de bens culturais e sua relação com as intervenções práticas. O ciclo de conferências destinado aos estudantes da pós-graduação, mas aberto a especialistas e interessados na área, contou com a participação de vários professores universitários de São Paulo, Minas Gerais, Rio de Janeiro e Pará, e de muitos técnicos de órgãos de preservação, em especial do DPH, do Condephaat e da Regional do Iphan de São Paulo e do Rio de Janeiro, configurando-se como importante evento da área da preservação.

As seis resenhas que integram esta edição revelam o dinamismo editorial do campo arquitetônico. Architettura contemporanea: Brasile; Preservação do patrimônio arquitetônico da industrialização: Problemas teóricos de restauro; O florescer das cores - A arte do período Edo; Debates e proposições em arquitetura, urbanismo e território na era industrial. Modernidade verde. Jardins de Burle Marx; e The environmental performance of tall buildings são obras referenciais de suas áreas, cujas respectivas resenhas de Maria Alice Junqueira Bastos, Eneida de Almeida, Paulo Yassuhide Fujioka, Marcos Virgílio da Silva, Vladimir Bartalini e Roberta Consentino Kronka Mülfarth apontam suas contribuições às áreas da história da arquitetura, da produção brasileira contemporânea, da preservação arquitetônica, da trajetória de arquitetos, do paisagismo e da relação da arquitetura com o meio ambiente.

Esperamos que o conteúdo desta edição cumpra seu objetivo de fomentar a troca de idéias, estimulando novas investigações e contribuindo para a consolidação da pesquisa em arquitetura.

Boa leitura.

Mônica Junqueira de Camargo

Editora-chefe 